\title{
BMJ Global Health Using spatial analysis and GIS to improve planning and resource allocation in a rural district of Bangladesh
}

\author{
T A Robin, ${ }^{\oplus 1}$ Marufa Aziz Khan, ${ }^{1}$ Nazmul Kabir, ${ }^{1}$ Sk Towhidur Rahaman, ${ }^{1}$ \\ Afsana Karim, ${ }^{1}$ Imteaz Ibne Mannan, ${ }^{2}$ Joby George, ${ }^{1}$ Iftekhar Rashid ${ }^{\circledR 3}$
}

\begin{abstract}
To cite: Robin TA, Khan MA, Kabir N, et al. Using spatial analysis and GIS to improve planning and resource allocation in a rural district of Bangladesh. BMJ Glob Health 2019;4:e000832. doi:10.1136/ bmjgh-2018-000832
\end{abstract}

Handling editor Seye Abimbola

Received 19 March 2018

Revised 2 August 2018

Accepted 3 August 2018

\section{Check for updates}

C) Author(s) (or their employer(s)) 2019. Re-use permitted under CC BY-NC. No commercial re-use. See rights and permissions. Published by BMJ.

${ }^{1}$ MaMoni Health Systems Strengthening Project, Save the Children International, Dhaka, Bangladesh

${ }^{2}$ Hemayat Project, Jhpiego Afghanistan, Kabul, Afghanistan ${ }^{3}$ United States Agency for International Development (USAID), Dhaka, Bangladesh

Correspondence to

TA Robin;

ta.robin@savethechildren.org

\section{ABSTRACT}

The application of a geographic information system (GIS) in public health is relatively common in Bangladesh. However, the use of GIS for planning, monitoring and decision-making by local-level managers has not been well documented. This assessment explored how effectively local government health managers used maps with spatial data for planning, resource allocation and programme monitoring. The United States Agency for International Development-funded MaMoni Health Systems Strengthening project supported the introduction of the maps into district planning processes in 2015 and 2016. GIS maps were used to support the prioritisation of underserved unions (the lowest administrative units) and clusters of disadvantaged communities for the allocation of funds. Additional resources from local government budgets were allocated to the lowest performing unions for improving health facility service readiness and supervision. Using a mixed-methods approach, the project evaluated the outputs of this planning process. District planning reports, population-based surveys, local government annual expenditure reports and service availability and utilisation data were reviewed. The goal was to determine the degree to which district planning teams were able to use the maps for their intended purpose. Key informant interviews were conducted with upazila (subdistrict) managers, elected government representatives and service providers to understand how the maps were used, as well as to identify potential institutionalisation scopes. The project observed improvements in health service availability and utilisation in the highest priority unions in 2016. Quick processing of maps during planning sessions was challenging. Nevertheless, managers and participants expressed their satisfaction with the use of spatial analysis, and there was an expressed need for more web-based GIS both for improving community-level service delivery and for reviewing performance in monthly meetings. Despite some limitations, the use of GIS maps helped local health managers identify health service gaps, prioritise underserved unions and monitor results.

\section{BACKGROUND}

The geographical contextual factors, such as communication networks, distance from available health facilities and region of residence, are often key determinants of health

\section{Summary box}

- Geographic information systems have been used widely in national health programmes, including in Bangladesh, for planning, monitoring and evaluation. Literature on their use at the local level, however, is limited.

- Local health managers used maps during annual planning and for quarterly programme reviews. They were found to be helpful for better stakeholder engagement, prioritisation and resource allocation.

- The maps assisted with identifying clusters of underserved areas.

- Managers felt that they needed autogenerated maps for performance monitoring, as they lack the skills to generate them themselves.

- The Government of Bangladesh is introducing a paperless electronic management information system with autogenerated maps to support the effective use of routine data by managers and prioritise underserved areas.

outcomes for women and children. ${ }^{1-4}$ Health outcome inequalities (eg, neonatal, infant and child mortality) often then have a spatial effect, with clusters of inequality concentrated in certain geographic areas. ${ }^{15}$ In Bangladesh, the demographic and health surveys from the past decade show a persistently higher neonatal and child mortality in the eastern half of the country. ${ }^{6} 7$ From 1997 to 2014, Sylhet, a north-eastern division, has been showing the highest neonatal, infant and under-5 mortality rate. ${ }^{46}$ Additionally, in Bangladesh, women and their families face barriers to accessing skilled delivery services, such as long distance to facilities and poor road conditions. ${ }^{8}$ Hence, it is important that we carefully plan and monitor not only biological and behavioural factors but also these geographical contextual factors. Therefore, understanding the geographic determinants 
in making health programming decisions may support the improvement of service availability, access, utilisation and outcomes. ${ }^{3910}$

Globally, a geographic information system (GIS) with dynamic analytical and visual presentation capabilities is a widely used technology in health sector planning. The importance of GIS mapping in health programme monitoring and displaying performance indicators is highlighted in various studies ${ }^{3611}$ despite the arguments of high cost and limitations in technical knowledge. ${ }^{12} 13$ For example, countries like Kenya, Ghana, Rwanda and Malaysia have applied this technology to data-driven health decision-making. ${ }^{14-17}$ Countries like Canada have used it to monitor the spread of West Nile virus. ${ }^{18}$ Kenya used health facility mapping for planning, and Indonesia used it for regular monitoring of its heath programmes. The example in Rwanda showed its applications for monitoring routine service data. ${ }^{314}$ Much literature also exists on the use of spatial analysis in health programmes. ${ }^{3} 1920$ The visual format of information presentations with respect to geography facilitates the spatial analysis of existing health services and specific populations to identify areas where programmes need to invest. ${ }^{13} 1921$ In particular, a few journals suggest that maps can be used to visually display health service utilisation overlaid with factors related to locational constraints and others, including access barriers. ${ }^{1322} 23$

The use of GIS technology in public health is common in Bangladesh. Immunisation and disaster management interventions extensively use GIS capabilities. ${ }^{24}$ Various public institutions have used this technology as well; for instance, the Bangladesh Bureau of Statistics and the Local Government Engineering Department in Bangladesh are doing so. ${ }^{25}$ The Ministry of Health and Family Welfare (MOHFW) in Bangladesh recently began using spatial tools in health policy decision-making. ${ }^{26}$ The Directorate General of Health Services, within the MOHFW, has integrated web-based GIS into its district health information system (DHIS2) to visualise routine data ${ }^{27}$ and improve programme monitoring and evaluation.

A gradual shift in health programme planning occurred with the advancement in map integration within the government's management information system (MIS). After 1998, major changes were implemented in health, nutrition and population programme planning to enable the delivery of cost-effective and integrated health services. ${ }^{28}$ After the first two phases of a sector-wide approach, the planning process shifted from centralised to district-level planning. The intentions were to harmonise the delivery of healthcare services, increase the availability and utilisation of services, strengthen health systems and improve health and family planning services. ${ }^{2}{ }^{28}$ Through this approach, programmes are guided by an operational plan led by each programme director. Budgeted activities are monitored using performance indicators. Thus, the monitoring of the programme and review of performance indicators are important.
An increasing number of research activities have been performed in developing nations related to GIS and health. ${ }^{20}$ However, use of GIS for planning, monitoring and decision-making by local-level health managers in Bangladesh has not been well documented.

\section{DECENTRALISED DISTRICT PLANNING PROCESS IN HABIGANJ}

The MaMoni Health Systems Strengthening (MaMoni HSS) project, a United States Agency for International Development-funded project, supported district-level managers in the MOHFW in conducting decentralised district planning in Habiganj District, a subdivision of Sylhet Division, in fiscal years 2015, 2016 and 2017 (July to June). The district had a projected population of 2313 998 in 2017. The district has 77 unions and 8 upazilas, with a total area of $2636.59 \mathrm{~km}^{2}$, of which $149.48 \mathrm{~km}^{2}$ is forested.$^{29}$ Paved roads connect most of the upazila head offices, and about $77 \%$ (2753.88 $\mathrm{km})$ of road is unpaved. Rivers and canals are the major communication routes during monsoons. ${ }^{30}$

Our project, with an intention of facilitating data-driven decision-making, introduced a decentralised district planning process. In particular, the objectives were to identify low-performing unions, identify and prioritise area-specific strategies to improve the performance, and provide a platform for ongoing review, monitoring and evaluation of progress. Figure 1 shows the process flow diagram with steps for the decentralised planning process; it mentions where we applied spatial analysis and GIS mapping.

The district planning process coincided with the budget allocation of elected representatives and councils (parishads) at the union and upazila level. The district planning process involved advocating with the local government and elected representatives to allocate resources for improving health services. The local governments are tasked with spending around $10 \%$ of their budget on the health sector. ${ }^{31}$

The current process evaluation explored how the managers used maps for decentralised planning, better prioritisation and allocation of resources. Since April 2015, MaMoni HSS introduced maps incorporating spatial data into the decentralised planning process. GIS was used to visually present information on the level of service utilisation and availability of service providers and health facilities. The lowest administrative level (union) was used as the unit of presentation. ArcGIS software was used to generate maps, and the maps were customised according to need of the health and family planning managers at the district and upazila level. Information from all unions and upazilas was plotted and used in the planning process.

Figure 2A,B provides illustrative examples of the maps used in the district planning. Figure 2A shows unionlevel performance of skilled birth attendants (SBA) and identified low-performing unions based on the service utilisation status of antenatal care, postnatal care, SBA 


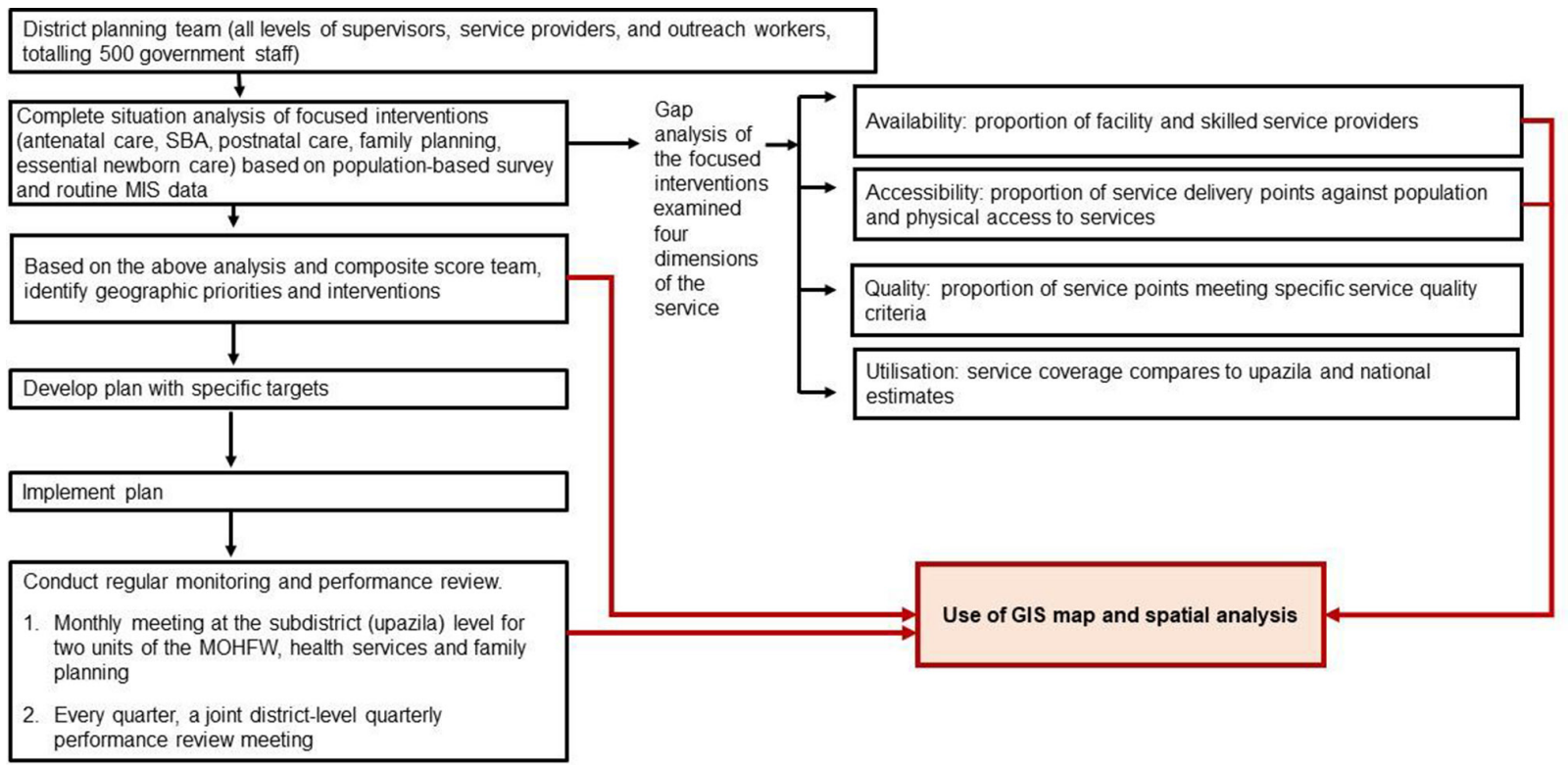

Figure 1 The steps in decentralised district planning process. GIS, geographic information system; MIS, management information system; MOHFW, Ministry of Health and Family Welfare; SBA, skilled birth attendant.

services, initiation of breast feeding and use of modern contraceptives. The shape files of the union and upazila administrative boundaries were obtained from the Local Government Engineering Department in Bangladesh. The geo-coordinates of the facilities were collected by the project staff and then plotted to create facility maps. Figure 3 shows which unions offered normal delivery and neonatal care services, indicated by the availability of a health facility and a skilled female service provider (family welfare visitor, or FWV), defined as a female government service provider who has completed 18 months of training, including 6 months of midwifery training.

\section{EVALUATING HOW GEOGRAPHIC INFORMATION SYSTEM WAS USED IN DECENTRALISED DISTRICT PLANNING AND MONITORING}

A mixed-methods approach was used (document review/ key informant interview). The combination of data
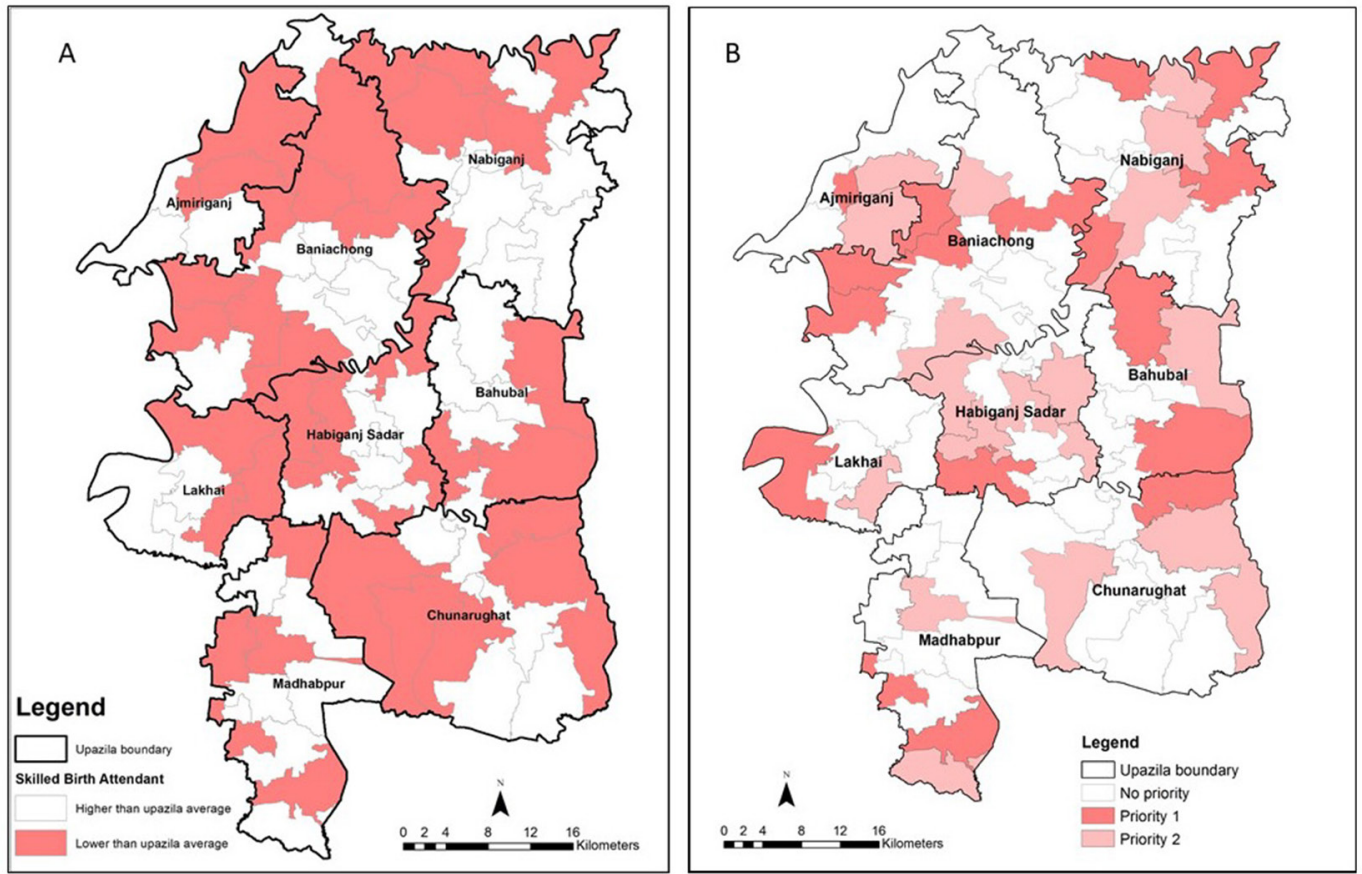

Figure 2 (A) Map of skilled attendance at birth. (B) Unions prioritised by composite score in Habiganj District, by union, used in April 2015. 

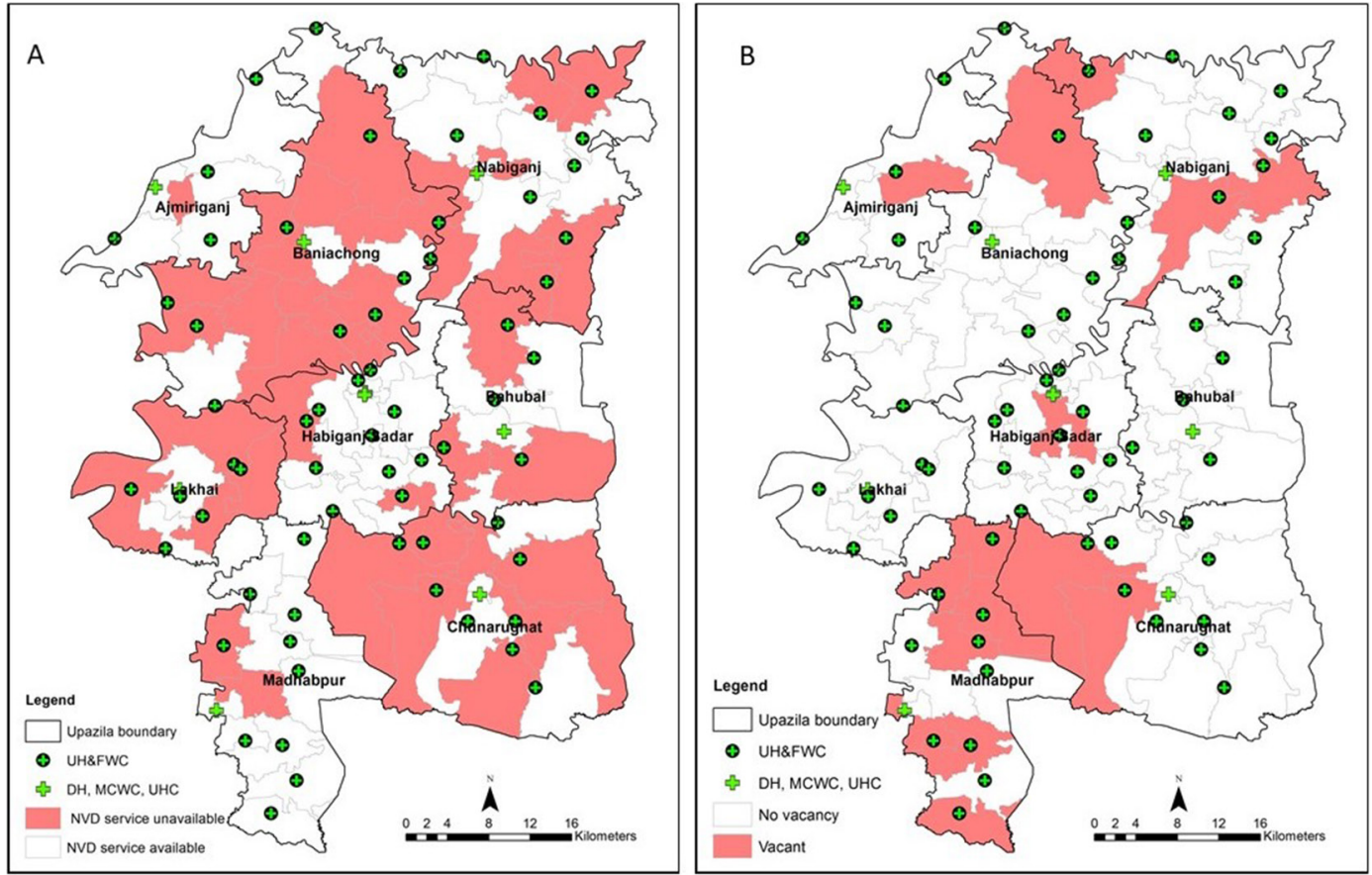

Figure 3 (A) Facilities with normal vaginal delivery (NVD) service and (B) unions with trained female service provider (family welfare visitor, FWV), Habiganj, as of April 2015. DH, district hospital; MCWC, mother and child welfare centre; UHC, upazila health complex; UH\&FWC, union health and family welfare centre.

sources included project and government MIS, which were used to investigate the specific questions mentioned in table 1.

The assessment reviewed the district planning process reports and upazila plans generated from the exercise to understand whether and how the maps were used. Particularly, the evaluation asked whether the underperforming clusters were mentioned in the plans as a priority, and whether those unions received additional resource allocation from the MOHFW or local government. Each union's annual expenditure report was collected to track investment in the health sector.

The project conducted facility readiness assessments of all facilities every 6 months as part of programme monitoring. The assessment compared data from 2015 and 2016 to determine if service or staff availability changed during that time.

Reports and presentations from special events, such as a safe motherhood day celebration, and minutes from joint quarterly performance review meetings were

Table 1 Evaluation questions, data collection process and sources

Evaluation questions Data collection process Data sources/participants

\begin{tabular}{lll}
\hline $\begin{array}{l}\text { How effectively did the managers use } \\
\text { maps in programme planning and } \\
\text { setting geographical priority? }\end{array}$ & $\begin{array}{l}\text { Document review, key informant } \\
\text { interview }\end{array}$ & $\begin{array}{l}\text { Population-based surveys, facility assessments, } \\
\text { reviews of district plans, district and upazila } \\
\text { managers of governmental and non-governmental } \\
\text { organisations }\end{array}$ \\
$\begin{array}{l}\text { To what extent did the use of maps } \\
\begin{array}{l}\text { and spatial analysis lead to better } \\
\text { resource allocation? }\end{array}\end{array}$ & $\begin{array}{l}\text { Document review, key informant } \\
\text { interview }\end{array}$ & $\begin{array}{l}\text { Local government annual expenditure reports, } \\
\text { facility assessments, district and upazila } \\
\text { managers of governmental and non-governmental } \\
\text { organisations }\end{array}$
\end{tabular}

$\begin{array}{lll}\text { How effectively did the managers use } & \text { Document review, key informant } & \text { Government management information system } \\ \text { maps in programme monitoring? } & \text { interview } & \begin{array}{l}\text { reports, event reports of day observations and } \\ \text { quarterly review meetings, district and upazila }\end{array} \\ & & \text { managers of governmental and non-governmental } \\ \text { organisations }\end{array}$

What are managers' views on spatial Key informant interview District and upazila managers of governmental and data and geographic information non-governmental organisations

system map use? 
examined to assess how the programme monitoring managers used the maps. The document review also examined maternal and neonatal death maps, which were plotted from government MIS data, and used them in planning consultations. After that, we compared the status with the 2016 findings to assess whether any changes occurred.

Five key informants were selected and interviewed. All participated in the planning process. We selected them based on their ability to provide perceptions on map use and potential scopes for institutionalisation from various layers of management. We ensured the participation of government managers, project managers, local government representatives and service providers. We asked them selected questions (specifically mentioned in table 1), then collected their answers and put relevant quotes in the appropriate context of the manuscript. Three upazila managers from the MOHFW, one implementing non-governmental organisation staff member, one elected local government representative and one FWV, were selected. The evaluation assessed their involvement in use of maps, their perception about the process and the feasibility of integrating GIS data into routine decision-making.

\section{USE OF SPATIAL DATA IN PROGRAMME PLANNING}

The district planning process reports confirmed that the maps produced by GIS were used by the managers and service providers during the problem identification process, and were referred to in the advocacy and resource allocation processes. According to one manager, this visualisation technique enabled data sharing in an open and interactive way. The maps got service providers and supervisors more involved in planning workshops. The use of maps allowed groups with different compositions of health cadres to compare the situation of different indicators. During planning meeting, the utilisation level of antenatal care, postnatal care, SBA services, initiation of breast feeding and use of modern contraceptives indicators were compared against the upazila averages of respective indicators. One upazila manager stated that he/she considered each of the indicators separately for each union. In many cases, some indicators of a union were below average, though not all. Therefore, the participants first identified the low and high-performing unions for each indicator (see figure 2A). Figure 2B shows 35 unions that were identified as low performing, meaning at least three indicators were below the upazila average. Priority 1 unions were classified as when the percentages of all five indicators were under the average upazila percentage. Priority 2 union means any four indicators were under the average upazila percentage. Based on the findings of the priority score (figure 2B) and considering situations of workforce vacancy and facility preparedness (figure 3), service providers jointly identified 16 priority unions for which they developed action plans with specific targets. We observed that in 10 of 16 identified unions, service utilisation was low.

It should be noted that primary-level health services providers in union-level facilities had already been using hand-drawn maps before the study. Thus, the computer-drawn maps were an incremental introduction for managers, not a completely new concept. The managers may have reacted positively to the use of maps in programme planning because they were generated by the project and not by their own statisticians.

\section{USE OF SPATIAL DATA IN PROGRAMME MONITORING}

Usually, local managers shared the status of service coverage with MIS data at monthly and quarterly review meetings. Moreover, district and upazila-level administration observed special days, like immunisation week, safe motherhood day, and so on. Event reports on national safe motherhood day celebrations and quarterly performance review meetings at the district level revealed that managers used spatial data and maps for programme monitoring. Maternal and neonatal death information collected from regular government MIS was plotted in GIS maps and presented at every safe motherhood day observation to sensitise local managers about the current situation. Figure 4 shows the number of neonatal deaths in facilities and communities between May 2014 and April 2015, and between May 2015 and April 2016. Geographically, the northwestern part of the district is designated as wetland (haor), and road connections are mostly influenced by seasonality. The south-eastern part is covered with tea garden. As a result, providers could not visit all parts of the area due to difficult communication systems; consequently, under-reporting was the most common issue. In meetings with local managers, they were made aware of under-reporting, and they ensured that community service providers visited hard-to-reach areas. Figure 4B shows that death notification increased in 2016 compared with the previous year. Managers reported that this kind of map helped them identify high clusters of death and reporting gaps.

\section{PRIORITISATION AND ALLOCATION OF RESOURCES}

This section discusses the effectiveness of map use by analysing whether the prioritised union received additional resources and showed improvement in normal delivery services. A manager expressed that using the map made it easy to track whether additional resources needed to be allocated to the lowest performing unions. It also helped managers track the health service statistics of unions that received more investment. The manager mentioned that he previously did it by reading data in digits, which sometimes could be monotonous during a daylong workshop. Maps make reviewing data easy and interesting for district planning team members. 

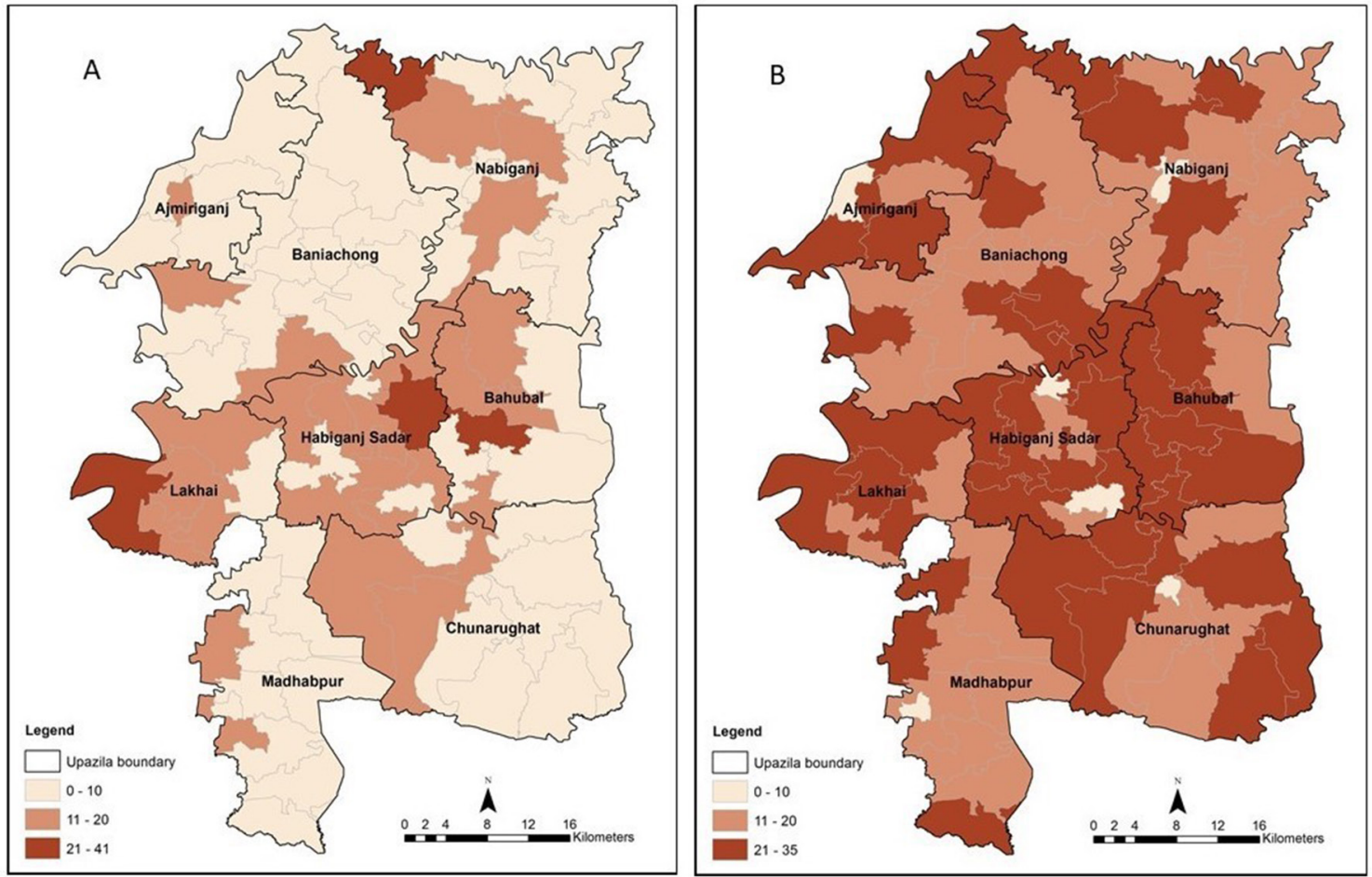

Figure 4 (A) Number of annual neonatal deaths between May 2014 and April 2015 and (B) between May 2015 and April 2016, Habiganj District.

The local government leader interviewed described the advantage of mapping analysis in the district planning workshop. He said that using maps helps him figure out why certain areas are underserved, since he knows about the contexts of his area, like road connections. He noted that it would be even better if he could see those views in the maps to plan resource allocation for his department. Record review observed that local governments invested their own funds in medicine and waste management in fiscal year 2015-2016.

Moreover, evidence suggested that the health managers were able to channel funding from outside the health sector to priority unions. Figure 5 shows budget utilisation for 11 out of 16 priority unions increased from fiscal year 2015 to 2016. Then again, figure 6 compares the number of $24 / 7$ service delivery points in 2015 and 2016. In 2015, many unions did not have a $24 / 7$ delivery service (figure 6A). Many people were dependent on upazila and district-level facilities, which were often too far away. The assessment observed an increase in number of $24 / 7$ union-level facilities in 2016. In 2015, local governments identified underserved unions, and over the year, they upgraded seven union-level facilities to be open $24 / 7$.

However, in the planning phase, the managers focused on strategically located unions, taking into consideration available human resources and facility readiness. The non-governmental organisation project manager mentioned that some unions without a health facility or service provider available were not prioritised, as they believed it would be difficult to show improvement in those unions due to factors beyond their control.

\section{DIFFERENT SCOPES TO INSTITUTIONALISE USE OF SPATIAL DATA}

The interview with service providers and with government and non-governmental organisation managers

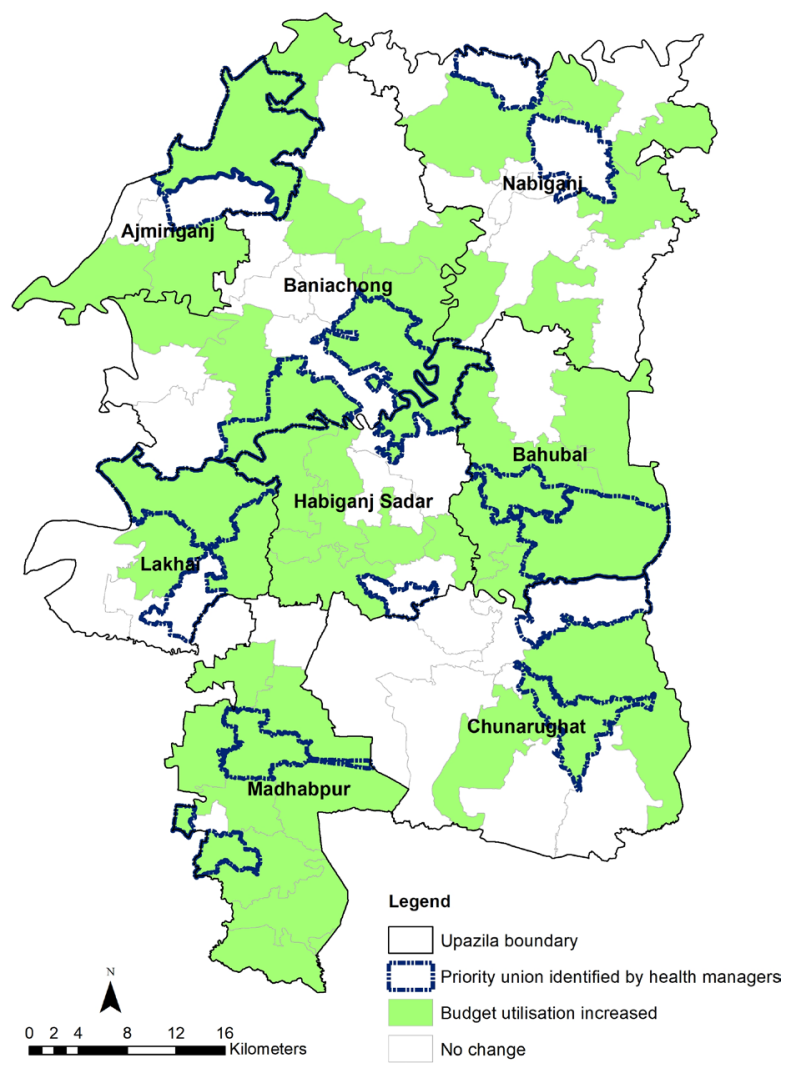

Figure 5 Unions where Union Parishad budget utilisation increased from April 2015 to April 2016. 

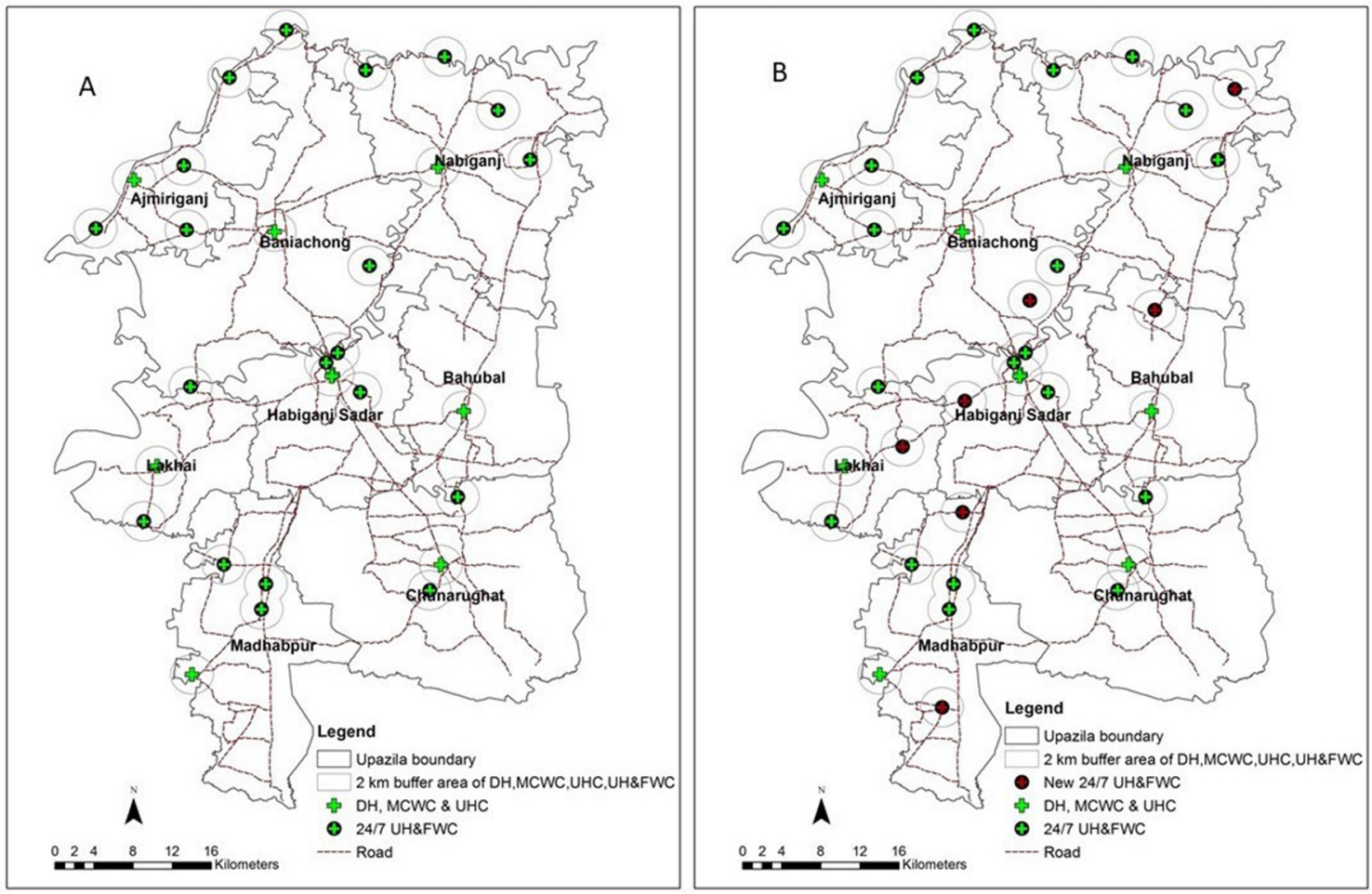

Figure 6 (A) Unions where 24/7 facilities were available in 2015. (B) Unions where 24/7 facilities were available in 2016. DH, district hospital; MCWC, mother and child welfare centre; UHC, upazila health complex; UH\&FWC, union health and family welfare centre.

identified current practices and potential scopes for incorporating spatial analysis into regular service delivery and planning mechanisms.

The plans that were developed during district planning process were reviewed every month at the upazila level and every 3 months at district-level quarterly performance review meetings. Government staff participate in this meeting. District and upazila managers suggested incorporating some maps from those performance data that are only in graphical formats into quarterly performance review meetings. One of the clinical managers commented that sometimes, graphical presentations were not enough. Maps on performance more clearly showed what had been done in their own upazilas.

Outreach workers, known as family welfare assistants, and FWVs use hand-drawn maps of their catchment areas to track pregnant women because of a previous project focusing on community mobilisation. One of the managers mentioned that union health and family welfare centres, the union-level health facilities, have been using expected date of delivery maps from 2013 in Habiganj for planning monthly services for mothers. Currently, these maps are manually drawn by FWVs using the information on pregnant women from family welfare assistant registers. One of the FWVs cited in her interview that she and her team use these maps to visually understand their health facility's services and show them to visitors, such as government-level supervisors and those from non-governmental organisations.
However, supervisors have not had any system to use spatial data in supervision or performance monitoring activities. One of the upazila managers mentioned that the government is introducing a tablet-based, automated data recording and reporting system, called electronic MIS (e-MIS), in Habiganj District. The manager felt that these tablets would be able to produce customised maps from live data, meaning all monitoring systems could be automated.

One of the health managers recommended that maps coming from the MaMoni HSS project at this point should be provided by the government health system. The existing use of hand-drawn maps by community-based outreach workers suggests that, with limited support, it may be feasible to incorporate maps into programmes for service delivery planning and supervision. However, the Government of Bangladesh is introducing mapping tools in its regular MIS using the DHIS2 platform and e-MIS. The carefully planned, phased roll-out of e-MIS, the GIS-based decision support system, could become the norm.

\section{LIMITATIONS}

Limitations included measuring the relationship between GIS map use and the impact of the interventions. For instance, it was difficult to attribute the increase in resource utilisation only to use of spatial data, as resource mobilisation increased in general in the entire district. The local government 
representatives, in describing the resource allocation process, pointed out that the total annual funding is dependent on central decisions and is often somewhat beyond their control. Similarly, poorer unions may not have a revenue stream large enough to make a significant contribution to health service improvement. Another limitation was unavailability of a "comparison' district where the project interventions were not in place. Additionally, the small number of interviews conducted is another drawback. Further, an updated settlement shape file would have been helpful to determine the distance-based calculation of access to specific services. There were also gaps in the quality and timeliness of updates to data. This can have an undesirable effect on map products. The data quality issue in the regular government MIS made for challenges in preparing the deaths map. Also, more detailed information with household coordinates would be helpful for performing the spatial cluster analysis.

\section{LESSONS LEARNT}

The decentralised district planning process was comprehensive and involved all relevant stakeholders. Incorporating GIS technology into this planning process was a new approach in Bangladesh. Because of poor GIS capacity, geospatial outputs can be misinterpreted. Any country with similar low-resource settings should ensure an adequate budget before implementing the entire intervention. The GIS team, which might be a mix of project and government staffs, should initiate its groundwork well before the planning process to identify the possible mapping need and available information. We propose to use open-source systems, like QGIS, or mobile-based e-MIS with an interactive mapping application to make it a sustainable approach. Using GIS technology for decision support is costly, and the learning curve is steep. In particular, the initial capacity-building costs of government workers on e-MIS technology may hinder the net benefit returns.

\section{CONCLUSION}

Our project introduced GIS mapping at different steps of a decentralised planning process. The process evaluation observed that the data analysis with maps involved local health managers and service providers more for situation analysis and prioritising unions. Also, comparisons over 2 years showed increases in budget utilisation and upgradation of service delivery points in identified unions. Maps were also used in quarterly reviews and advocacy meetings to monitor performance indicators, and displayed improvements in death notification. The unavailability of more detailed spatial data limited further investigation. Despite limited resources and technical skills, our assessment suggests that the use of an e-MIS with a built-in mapping system could make it easier for government officials to use maps for planning. We strongly recommend that government managers undergo capacity building to use this technology, as that is necessary for its institutionalisation and sustainability. Finally, more participatory research is needed to identify the potential scopes of spatial data use in local government decision-making.

Acknowledgements My sincere gratitude goes to everyone who has contributed to the success of the research work. First, I thank Yordanos B Molla, senior monitoring, evaluation, and learning advisor at Pathfinder International, and Barbara Rawlins, monitoring and evaluation team leader at Jhpiego, for their technical support. Special thanks go to independent consultant Anna Williams for reviewing the writing style. Finally, I thank the United States Agency for International Development for the financial support.

Contributors All authors have participated sufficiently in the work to take responsibility for the content, including participation in the conception or design of the work, or the acquisition, analysis or interpretation of data and drafting the work. All authors were involved in the revision of article and the final version for publication. STR helped in data analysis. IIM, JG, AK and IR contributed in the design of the work and data interpretation. NK and MAK helped in data acquisition and interpretation of data. TAR developed the whole structure of the article and wrote the first draft.

Funding This study was funded by the United States Agency for International Development (grant number: AID-388-LA-13-00004).

Disclaimer The views expressed in this article are solely the views of the author and do not reflect the views of the United States Agency for International Development or the US Government.

Competing interests None declared.

Patient consent Not required.

Provenance and peer review Not commissioned; externally peer reviewed.

Data sharing statement No additional data are available.

Open access This is an open access article distributed in accordance with the Creative Commons Attribution Non Commercial (CC BY-NC 4.0) license, which permits others to distribute, remix, adapt, build upon this work non-commercially, and license their derivative works on different terms, provided the original work is properly cited, appropriate credit is given, any changes made indicated, and the use is non-commercial. See: http://creativecommons.org/licenses/by-nc/4.0/.

\section{REFERENCES}

1. Okwaraji YB, Cousens S, Berhane Y, et al. Effect of geographical access to health facilities on child mortality in rural Ethiopia: a community based cross sectional study. PLoS One 2012;7:e33564-8.

2. Ebener S, Guerra-Arias M, Campbell J, et al. The geography of maternal and newborn health: the state of the art. Int $J$ Health Geogr 2015;14:19.

3. Makanga PT, Schuurman N, von Dadelszen P, et al. A scoping review of geographic information systems in maternal health. Int $J$ Gynaecol Obstet 2016;134:13-17.

4. Huda TM, Tahsina T, El Arifeen S, et al. The importance of intersectoral factors in promoting equity-oriented universal health coverage: a multilevel analysis of social determinants affecting neonatal infant and under-five mortality in Bangladesh. Glob Health Action 2016;9:29741.

5. Gupta AK, Ladusingh L, Borkotoky K. Spatial clustering and risk factors of infant mortality: district-level assessment of high-focus states in India. Genus 2016;72:2.

6. National Institute of Population Research and Training, Mitra and Associates, ICF International. Bangladesh demographic and health survey 2014. Dhaka, Bangladesh, and Rockville, MD, USA: National Institute of Population Research and Training and ICF International, 2016.

7. Bangladesh Bureau of Statistics. Report on Bangladesh sample vital statistics 2016. Dhaka, Bangladesh: Bangladesh Bureau of Statistics, 2017.

8. Story WT, Burgard SA, Lori JR, et al. Husbands' involvement in delivery care utilization in rural Bangladesh: a qualitative study. BMC Pregnancy Childbirth 2012;12:28.

9. Johnson FA, Frempong-Ainguah F, Matthews Z, et al. Evaluating the impact of the community-based health planning and services 
initiative on uptake of skilled birth care in Ghana. PLoS One 2015;10:e0120556.

10. Beale L, Abellan JJ, Hodgson S, et al. Methodologic issues and approaches to spatial epidemiology. Environ Health Perspect 2008;116:1105-10.

11. Lippeveld T, Sauerborn R, Bodart C. Design and implementation of health information systems. Geneva, Switzerland: World Health Organization, 2000.

12. Dunn CE, Atkins PJ, Townsend JG. GIS for development: a contradiction in terms? Area 1997;29:151-9.

13. Hernandez JH, Akilimali P, Kayembe P, et al. The value of spatial analysis for tracking supply for family planning: the case of Kinshasa, DRC. Health Policy Plan 2016;31:1058-68.

14. Noor AM, Alegana VA, Gething PW, et al. A spatial national health facility database for public health sector planning in Kenya in 2008. Int J Health Geogr 2009;8:13.

15. Gething PW, Johnson FA, Frempong-Ainguah F, et al. Geographical access to care at birth in Ghana: a barrier to safe motherhood. BMC Public Health 2012;12:991.

16. Hazrin H, Fadhli Y, Tahir A, et al. Spatial patterns of health clinic in Malaysia. Health 2013;05:2104-9.

17. Sudhof L, Amoroso C, Barebwanuwe P, et al. Local use of geographic information systems to improve data utilisation and health services: mapping caesarean section coverage in rural Rwanda. Trop Med Int Health 2013;18:18-26.

18. Gosselin P, Lebel G, Rivest S, et al. The Integrated System for Public Health Monitoring of West Nile Virus (ISPHM-WNV): a real-time GIS for surveillance and decision-making. Int J Health Geogr 2005;4:21.

19. Fradelos EC, Papathanasiou IV, Mitsi D, et al. Health based geographic information systems (GIS) and their applications. Acta Inform Med 2014;22:402-5.

20. Lyseen AK, Nøhr C, et al. A review and framework for categorizing current research and development in health related geographical information systems (GIS) studies. Yearb Med Inform 2014;9:110-24.
21. Colston JM, Burgert CR. Using geospatial analysis to inform decision making in targeting health facility-based programs: a guidance document. Chapel Hill, NC, USA: MEASURE Evaluation, 2014.

22. McLafferty SL. GIS and health care. Annu Rev Public Health 2003;24:25-42.

23. Musa GJ, Chiang PH, Sylk T, et al. Use of GIS mapping as a public health tool-from Cholera to cancer. Health Serv Insights 2013;6:HSI. S10471-6.

24. Sugimoto JD, Labrique AB, Ahmad S, et al. Development and management of a geographic information system for health research in a developing-country setting: a case study from Bangladesh. $J$ Health Popul Nutr 2007;25:436-47.

25. Rahman N, Sardar ZH. Integrating Statistical and geospatial information system: Bangladesh perspective. Dhaka, Bangladesh: Bangladesh Bureau of Statistics, 2014.

26. Kim D, Sarker M, Vyas P. Role of spatial tools in public health policymaking of Bangladesh: opportunities and challenges. $J$ Health Popul Nutr 2016;35:8.

27. Ahmed T, Bloom G, Iqbal M. E-health and M-health in Bangladesh: opportunities and challenges. Brighton, UK: Institute of Development Studies, 2014.

28. Ahsan KZ, Streatfield PK, ljdi RE, et al. Fifteen years of sector-wide approach (SWAp) in Bangladesh health sector: an assessment of progress. Health Policy Plan 2016:31:612-23.

29. Bangladesh Bureau of Statistics. Community report Habiganj Zila June 2012 population and housing census 2011. Dhaka, Bangladesh: Bangladesh Bureau of Statistics, 2012.

30. Bangladesh Bureau of Statistics. District statistics 2011 Habiganj. Dhaka, Bangladesh: Bangladesh Bureau of Statistics, 2013.

31. Ahmed SM, Alam BB, Anwar I. Bangladesh health system review. Health Syst Transit 2015;5. 